\title{
Mindset Kinetics in Management and Business World
}

Mauro Luisetto*

European Specialist in Laboratory Medicine, Hospital Pharmacist’s Manager, Italy

"Corresponding author: Mauro Luisetto, European Specialist in Laboratory Medicine, Hospital Pharmacist's Manager, Italy. Tel: +393402479620; Email: maurolu65@gmail.com

Citation: Luisetto M (2018) Mindset Kinetics in Management and Business World. Arch Bus Adm Manag: ABAM-103. DOI: 10.29011/ABAM-103. 100003

Received Date: 09 March, 2018; Accepted Date: 19 March, 2018; Published Date: 28 March, 2018

\begin{abstract}
Cats in hunting not use gloves (action) is a common phrase in business settings but to this is really crucial to adequately know some human mindset kinetics. (The kinetics thinking way of human being) In order to make the right decision-making activity in really hard and critical situation a deep knowledge in some mindset kinetics can given helpful instrument. In this review we to observe some literature involved in this interesting approach (our social and business Relationship)
\end{abstract}

Keywords: Business; Coping strategies; HR management; ICT information communication technologies; Management; Mindset kinetics, Stress management

\section{Introduction}

In management and business settings relevant role is played by human factor and ability to adequate Set the problems in order to choose the really best solution also in very difficult situations. In this process mindset kinetics knowledge can play crucial factors since to be considered as a strategic tool for managers. In example we can see what happen in some trade events: in some situation all buy or in other many Subjects sell their business stokes properties (under emotional influence).

Other situation involved for example in little time available to close a business or a transaction. (In example in condition of few information scenario.) A deep knowledge in mindset kinetic can help in this situation.

According short communication "Mindset Kinetics-Under Toxicological Aspect" published in 2018 was reported that:

"Can we compare the mindset kinetics to other metabolic kinetics? Are really so different these aspects?

Can we think to a sort of saturate condition in some situation?

Can we think to a maximal velocity in management of simultaneous or high stress ant stimulus?

Why some individuals react in very different way?
Can we apply E. Goldratt TOC Theory of constraints in this kind of situations to explain some Psychological pathways?

Brain and mind follow the same principle? (Limitating factors?)" [1]. So psychological and beahviour Characteristic and skills like:

Emotional and social intelligence, aggressivity management, communication ability, proactive vision, Strategy, tactics, goal setting , take risk ability, problem solving, political competencies, self-esteem Resilience, perseverance, critical thinking, decision making in critical situation, learning by errors Change the frame of situation, no mental traps, stress management and coping strategy Emotional indifference, flexibility, no extreme thinking, negotiation ability, use well opportunities Rapidly sto cause of trouble, rapid feedback information are only some psychological - behavior Skills in today business setting uses as efficacy tools to solve every day problems Delay in response strategy to better decision making, bamboo theories, not delay decision, time management, goal setting, walking around management, MBO, lateral thinking and many other Are strictly managed by mindset kinetics systems and influenced by personal psychological and behavior attitudes and skills .

\section{Material and Methods}

With an observational approach we have find some relevant literature to produce a working hipotesys in the righ instrument in management and business activity. 


\section{Results}

From literature we can find related or emotional social intelligence or related communication abilities: "We can observe that in order to evaluate stressing situation are fundamental: kind of stress (in example HIGH or not); amount of global stressing condition, simultaneous; Duration of stimulus (chronic conditions?) individual status (resilience?, stress management ability, depression) psychologic but also genetic; kinetics. We have seen that in order to improve resilience abilities are use full many techniques in order to balance the mindset activity, If unbalanced results in an inadequate kinetics with an inappropriate global response. We think that also this condition must be evaluated under a kinetic- toxicological aspect to clear the basic Phisio-patogenetic movens"[1].

"About $70 \%$ of works ability and success depends on emotional intelligence versus $30 \%$ technical abilities (Remember Pareto paradigm 20/80 similar). The emotional intelligence theory shows that the emotional brain can be more rapid in responding to some stress stimulus then the rational thinking" [1].

"About $70 \%$ of works ability and success depends on emotional intelligence versus $30 \%$ technical abilities (Remember Pareto paradigm 20/80 similar). The emotional intelligence theory shows that the emotional brain can be more rapid in responding to some stress stimulus then the rational thinking [2].

"Amygdala is activated in some condition such as anger. Anxiety, fear, predatory behavior, aggressive behavior, and defense or subjugates behavior. Emotion: behavior and physiological response (vegetative and hormonal) involved in behavior and communication adjustment [3].

"Creativity is improved in high way using the new technologies (universal brain) and this can be added to the classic lateral thinking methods (De bono). Emotional intelligence (GOLEMAN) is great influenced by social media (digital generation) and their economic choice, the E. GOLDRATT theory of constraints is easily verified with informatics methods. The same we can see for Pareto paradigm (high number of follower vs. low). The military techniques (Eisen howermatrix) used time management instrument to achieve goals" [4].

"We can say that using velocity management strategy we can have efficient management decision making system to be applied to many project, reducing heavily the total cost (about $60 \%$ ) and improving the final endpoint. Using ICT PRINCIPLE added to professional social media tools and velocity management strategy we can Have HIGH performance in decision making system much more than classic management theories. ICT and communication trought social media power make the differences" [5].

"Also, in oriental medicine we can see body balances strategies, and also in some psychoanalytic techniques we can see that time is relevant to re-equilibrate some conditions (in example acute stress). We can think that the main factors involved are TIME and LONG REST in order to balance the physiologic functions" [6].

"Managers are told: Be global and be local. Collaborate and compete. Change, perpetually, and maintain order. Make the numbers while nurturing your people. To be effective, managers need to consider the juxtapositions in order to arrive at a deep integration of these seemingly contradictory concerns. That means they must focus not only on what they have to accomplish but also on how they have to think. When the authors, respectively the director of the Centre for Leadership Studies at the University of Exeter in the U.K. and the Cleghorn Professor of Management Studies at McGill University in Montreal, set out to develop a master's program for practicing managers, they saw that they could not rely on the usual MBA educational structure, which divides the management world into discrete business functions such as marketing and accounting. They needed an educational structure that would encourage synthesis rather than separation. Managing, they determined, involves five tasks, each with its own mind-set: managing the self (the reflective mind-set); managing organizations (the analytic mind-set); managing context (the worldly mind-set); managing relationships (the collaborative mindset); and managing change (the action mind-set). The program is built on the exploration and integration of those five aspects of the managerial mind. The authors say it has proved powerful in the classroom and insightful in practice. Imagine the mind-sets as threads and the manager as weaver. Effective performance means weaving each mind-set over and under the others to create a fine, sturdy cloth"[7].

"Building the skills of self-awareness, is using the assessment of one's emotions in directing behavior positively i.e. behaving logically and not letting emotions hijack one's behavior. When one faces paralyzing fear, thinking gets so clouded that one is not able to decide what to do. This is an example of emotional clouding mentioned earlier. Those who are able to understand and manage their emotions take the right course of action" [8].

But many other article talk about mindset ability and skills in business, management but also in social and other fields [7-21] And "In activation of amygdala the response is more rapid than when involved the frontal cortex"[15]. According velocity management strategy in healthcare "Creativity is improved in high way using the new technologies (universal brain) and this can be added to the classic lateral thinking methods (De bono). Emotional intelligence (GOLEMAN) is great influenced by social media (digital generation) and their economic choice, the E. GOLDRATT theory of constraints is easily verified with informatics methods. The same we can see for Pareto paradigm (high number of follower vs. low). The military techniques (Eisenhower matrix) used time 
management instrument to achieve goals. So, we think that also the Velocity Management Techniques must be added to the classic $\mathrm{c}$ core curriculum of the managers' schools and university.

This discipline used for example in military field or other discipline can be used also in health care to achieve the best economic results in the management of the systems. In this way we can have improving in business about $30-40 \%$ but in every way if not used the competitors will do it surely in order to apply this new management discipline we think That psychological and behavior skills are the golden keys to approach to these innovative instruments. Senior managers can in this way be at the same level of the young manager using specific techniques to rapidly learn new communication tools available today. So, the business Process can be modified to became more productive (transformation of input in output) Reducing costs, risks and improving economic results. The resource (manpower, technical resource, economic and financier and other) can be rationalized in more efficiently and rapid way" (17) and related role played by new social media "We think that core training must include Management, ICT, Professional social media, sharing economy principles, psychological behavior skills for team working, philosophy, theory and practical applications"[18].

\section{Conclusion and Discussion}

Observing some literature, we can say that in order to have the really best result in management is fundamental also to know the mindset kinetics and its consequences in right decision-making system as we as Strong instrument for resilience in many hard business situations.

Discipline like CHANGE MANAGEMENT, MBO, PROJECT MANAGEMENT, HR MANAGEMENT, TIME MANAGEMENT, CONFLICT MANAGEMENT and many other need strongly Psychological and behavior attitudes.

In example in to right searching information process, planning, deal process, problem solving, negotiation, trade and other business and economic, professionalism in business human relationship, no extremal thinking, no catastrophic thinking. To have right and efficacy decision making system also in critical setting a deeply knowledge in mindset kinetics and its consequences can give high performance level in business and management.

Trust in your instinct, forgives ability, think to the future, Changing sense of situation, No guilt sense (to make more free your mind, Attention to the distortion in communication, Rapidly stop the cause of trouble, before they increase (kill the monster before it increase) are only few examples in a complex world managed by our mind alone and interacting whit others.

A preliminary SWOT analysis can help in setting our or groups ability level in manage mindset kinetics to maximize the decision-making skills, Deming cycle added to E. Goldrad theories,
Goleman, Harris, DE bono and many other Researcher theory can help professionals in every business situation.

About $70-80 \%$ of probability of business success depends on emotional abilities and 30-20\% related technical ability. And according the Pareto paradigm: about $80 \%$ of the effects comes from $20 \%$ of the causes and business time is a great part of global living time. The global results in our business gives good outcomes in working settings but also in private life (family, social and other) And using strategy like velocity management, based in right decision-making process, we can have improving in business about $30-40 \%$.

High quality mangers know exactly what is right to do and the right time to do this to have the best results and often is possible is not a full rational decision. For this reason, we think that psychological and behavior skills are the golden keys to adequate management or business activity Also at political level we have seen recently that the velocity in stay tuned with people thinking can produce more effect in election strategies. So, we can say that we have a rational thinking, a lateral thinking but also an emotional-irrational thinking that can produce better results in some situation.

\section{References}

1. Luisetto M, Behzad N A, Ghulam R M (2018) Mindset Kinetics-Under Toxicological Aspect. Psychol Behav Sci Int J 8: 555731.

2. Mauro L (2017) Attitudes and Skills in Business Working Settings: A HR Management Tool. Bus Eco J 8: 291.

3. Luisetto M, Khan FA, Cabianca L, Mokbul MI, Rafa AY, et al. (2016) Amygdala pharmacology and crime behavior, dysfunctions to be considered as a disease? International Archives of BioMedicaland Clinical Research 2.

4. Luisetto M (2016) Velocity Management Strategy in Healthcare. J Bus Fin Aff 5: e148.

5. Luisetto M (2017) New Theories in Management Decision Making Systems luisetto m Innovative Journal of Business and Management 6: 1.

6. Luisetto M (2017) Intra- Local Toxicology Aspect Time Related in Some Pathologic Conditions. Open Acc J of Toxicol 2: 555586.

7. Gosling J, Mintzberg H (2003) The five minds of a manager. Harv Bus Rev 81:54-63,

8. Sanjiv Kumar, Vivek S Adhish, Abhimanyu Chauhan (2014) Managing Self for Leadership. Indian J Community Med 39: 138-142

9. Jamieson SD, Tuckey MR (2016) Mindfulness Interventions in the Workplace: A Critique of the Current State of the Literature. J Occup Health Psychol 22: 180-193.

10. Herrman H, Stewart DE, Diaz-Granados N, Berger EL, Jackson B, et al. (2011) What is resilience?. Can J Psychiatry 56: 258-265.

11. Zakariasen $\mathrm{K}$, Victoroff $\mathrm{KZ}$ (2012) Leaders and emotional intelligence: A view from those who follow. Healthc Manage Forum 25: 86-90. 
Citation: Luisetto M (2018) Mindset Kinetics in Management and Business World. Arch Bus Adm Manag: ABAM-103. DOI: 10.29011/ABAM-103. 100003

12. Dixon T (2012) Educating the Emotions from Gradgrind to Goleman. Res Pap Educ 27: 481-495.

13. Luisetto Mauro (2017) Jurisdictional Consequences in some brain condition. Neuro chem. Neuropharm 3:2.

14. Mauro Luisetto (2017) New Theories in Management Decision Making Systems. SF J Intel P R1:1.

15. luisetto M (2017) Brain and Transmission Signal Modulation. theranostic of brain disorder.

16. Sergerie K, Chochol C, Armony JL (2008) The role of the amygdala in emotional processing: a quantitative meta-analysis of functional neuroimaging studies. Neurosci Biobehav Rev 32:811-830.

17. Luisetto M (2016) Velocity Management Strategy in Healthcare. J Bus Fin Aff 5.
18. Luisetto M (2016) Sharing Economy and Healthcare Today: ICT, Knowledge, Skills, Projects, Practical Experience in Improving Clinical and Economic Outcomes. J Bus Fin Aff 5: 207.

19. Wen L, Yang H, Bu D, Diers L, Wang H (2018) Public accounting vs private accounting, career choice of accountingstudents in China. Journal of Accounting in EmergingEconomies 8: 124-140.

20. Singh S, Wang H, Zhu M (2017) "Perceptions of Social Loafing during the Process of Group Development". Midwest Academy of Management Conference Proceedings Chicago, Illinois. Workingpaper.

21. Singh S, Wang H, Zhu M (2017) Perceptions of Social Loafing in Groups: Role of Conflict and Emotions. 